\title{
Formulation, in-vitro and in-vivo pharmacokinetic evaluation of simvastatin nanostructured lipid carrier loaded transdermal drug delivery system
}

\author{
S Brito Raj ${ }^{* *}$, Kothapalli Bonnoth Chandrasekhar ${ }^{2}$ and Kesavan Bhaskar Reddy ${ }^{1}$
}

\begin{abstract}
Background: A simvastatin nanostructured lipid carrier loaded transdermal patch was developed to enhance the bioavailability and therapeutic effect.

Methods: Simvastatin NLC preparation was prepared by optimized hot homogenization technique and were characterized by particle size in nanometer, polydispersity index, zeta potential in millivolt, scanning electron microscopy, and entrapment efficiency by applying Box Behnken design utilizing multiple linear regression method.

Results: Chosen optimized NLC F7 formulation has particle size of $125.4 \pm 2.66 \mathrm{~nm}$, zeta potential of $-33.6 \pm 2.42$ $\mathrm{mV}$, and PI of $0.480 \pm 0.24$. The NLC was loaded in transdermal patch by solvent evaporation method and evaluated for physical characteristics, drug content, skin permeation studies, and in-vivo pharmacokinetic studies in male albino Wistar rat. In-vivo pharmacokinetic studies in NLC loaded transdermal patch show an increase in $\mathrm{AUC}_{0-\mathrm{a}}$ in $\mathrm{mg} / \mathrm{ml}$ when compared to marketed oral dosage form, which confirms the enhancement of bioavailability of simvastatin by NLC loaded transdermal patch.
\end{abstract}

Conclusions: From the data, it was concluded that drug-loaded NLC transdermal patch will be a promising drug delivery system for poorly bioavailable drugs.

Keywords: Antihyperlipidemic, Bioavailability, Box-Behnken design, Nanostructured lipid carrier, Transdermal drug delivery

\section{Background}

In recent research, the conventional drug delivery system is continuously trying to project the novel dosage forms due to various barriers of the drug to reach the systemic circulation like poor drug solubility and absorption, decrease in bioavailability due to rapid first pass metabolism, high fluctuation in plasma drug concentration level, and interaction due to drug and food. These factors are the major drawbacks in in-vivo pharmacological response which paves the way for failure of the conventional drug delivery system. Lipid nanoparticle

\footnotetext{
* Correspondence: britosraj@yahoo.co.in

'Department of Pharmaceutics, Centre for Pharmaceutical Nanotechnology, Sri Venkateswara College of Pharmacy, RVS Nagar, Chittoor, Andhra Pradesh, India

Full list of author information is available at the end of the article
}

acts as an alternative dosage form for the existing conventional particulate systems, like liposomes or polymeric nanoparticle [1].

Nanostructured lipid carriers (NLCs), a novel generation of solid lipid nanoparticle (SLNs), are the valuable alternative carrier to conventional systems such as solutions, ointments, and suspension [2]. NLC has a dual mixture of the solid lipid, and a spatially separated liquid lipid as the carrier, that were launched to overcome the high crystalline nature of lipid matrix and leakage of drug during storage in SLNs [3]. NLCs are depicted as a next level generation to SLN, because the nanostructure of lipid matrix is the combination of solid lipids with spatially arranged incompatible liquids. It has everincreasing drug loading efficiency because of preventing its expulsion in the recrystallization state by adding 
liquid lipid. Next to its higher drug loading ability, NLCs have superior biocompatibility, capability of scaling-up, and efficient control of drug release. Furthermore, current research points out that the NLCs could enhance the bioavailability and improve the permeability of the drug through tissues with a good tolerance [4].

Simvastatin is an HMG CoA reductase inhibitor, which decreases the low-density lipoprotein (LDL) level and triglycerides (TG) level in the blood and increases the highdensity lipoprotein (HDL) level. Simvastatin also helps to reduce the risk of stroke, heart attack, and other cardiac diseases in people with diabetes and coronary heart disease. The pharmacokinetic data of simvastatin like low bioavailability of $5 \%$, high protein binding capacity of $95 \%$, and it undergoes hepatic metabolism $\left(\mathrm{CYP}_{3} \mathrm{~A}_{4}\right)$ with very less biological half-life of $2 \mathrm{~h}$ paves the way to formulate it into NLC loaded transdermal patches [5].

NLC loaded transdermal drug delivery system administered through the transdermal route will increase the therapeutic effect of the loaded drug and reduce the dose to achieve the same therapeutic effects. It acts as a suitable dosage form for the low soluble and permeable drug by improving their bioavailability [6]. Nanostructured lipid carriers (NLC) act as a vehicle for coencapsulation, and also proposing a strategy for transdermal administration. By combining NLC carriers with common permeation enhancers will enhance the bioavailability very efficiently than other conventional dosage form. The combination of chemical enhancers with nanocarriers is an innovative approach to the design of a transdermal formulation [7].

Even though simvastatin is highly lipophilic (BCS Class II drug), it has been excreted very efficiently as an unchanged form in feces around $60 \%$ and $13 \%$ in renal on oral administration, which leads to reduction in bioavailability, i.e., only $5 \%$ of drug are bioavailable in blood for therapeutic effect [8]. The main intention of this research is to enhance the bioavailability of simvastatin by converting it into NLC loaded transdermal patch and also to discover a novel technique for the formulation of NLC based on optimization tooling. Another objective of this research is to perform the comparative pharmacokinetics studies in albino Wistar rats. The studies are carried out between the marketed formulation, simvastatin NLC, simvastatin-loaded transdermal patch, and simvastatin NLC loaded transdermal patch to prove the enhancement of bioavailability. This dosage form can bypass the hepatic metabolism and it will maintain the plasma drug concentration effectively to achieve the enhancement of bioavailability of simvastatin in blood.

\section{Materials and methods}

\section{Materials}

Simvastatin was acquired as a gift sample from Aurobindo Pvt Ltd. Hyderabad. Glyceryl dibehenate EP
Glyceryl behenate NF/CR (Compritol 888ATO) and Macrogol 6 Glycerol Caprylocaprate (Softigen) (Gatte Fosse Sas Saint - Press Cedex, France); Pluronic ${ }^{\bullet}$ F-68 (Poloxamer 188); Mono-(9Z)-9-octadecenoate sorbitan oleate (Span 80); poly vinyl alcohol (PVA); polyvinyl pyrrolidone (PVP); dimethyl sulfoxide (DMSO); propylene glycol (PG) (Sisco research laboratories Pvt. Ltd, Maharashtra, India). The following equipments are utilized for the formulation and evaluation of NLC: high-speed homogenizer (CAT, Germany); ultrasonicator (Q Sonica Germany); electronic balance (Schimadzu, Japan); FT-IR spectrophotometer (BRUKER, Germany); differential scanning calorimeter (DSC-60 Series, Schimadzu, Japan); nano particle size analyzer (Nanopartical Analyzer SZ 100 series, Horiba, Japan); Franz diffusion cell (Electro lab-EDC 07,India); stability chamber (Lab India Pvt. Ltd, India); HPLC (Waters-2695 series ,Bangalore, India). The following software are used for calculating the statistical data like PK solver (PharmPK); Design Expert 9 Software (Stat-ease, Inc. USA); Graph pad Prism (Version 7 software, USA).

In this study, all the procedures using albino Wistar rats, weighed $180-250 \mathrm{~g}$, male, $6-8$ weeks age, were provided by the Institutional Animal Ethical Committee of Sri Venkateswara College of Pharmacy, Chittoor, India and approved with certificates of conformity: SVCOP/ IAEC/004/2016-17. All animal procedures were approved by the Animal Ethics Committee of Sri Venkateswara College of Pharmacy.

\section{FTIR analysis}

FTIR was used to determinate the chemical interaction; drugs-excipients compatibility studies between simvastatin and other ingredients used in formulations. For this purpose, NLC dispersions were diluted with continuous phase water and centrifuged at 15,000 rpm for $40 \mathrm{~min}$. Residues were separately changed to glass plates and kept at $50{ }^{\circ} \mathrm{C}$ overnight to remove the aqueous phase. Samples were then used for FTIR analysis. Pure simvastatin, samples in the powder form, and NLC loaded transdermal transverse section layer were scanned over a wave number range of 4000 to $500 \mathrm{~cm}^{-1}$ at a resolution of $4 \mathrm{~cm}^{-1}$ in a FTIR instrument (Bruker, Germany) equipped with OPUS spectrum software. The sample was placed on the sample stage and always the same force (force gauge $100 \mathrm{~N}$ ) was applied to ensure reproducible contact between the sample and crystal for scanning. The system was operating in the transmission mode [9].

\section{Differential scanning calorimetry analysis}

DSC studies were used to determine the compatibility between drug and excipients; crystalline character of NLC formulation. DSC studies were carried out for simvastatin, compritol 888ATO, and drug-loaded NLC 
dispersion. These studies were performed by using DSC70, Schimadzu model instrument. Approximately weigh the samples for $5 \mathrm{mg}$ and were heated in aluminum pans with $20-200{ }^{\circ} \mathrm{C}$ at a rate of $20{ }^{\circ} \mathrm{C} / \mathrm{min}$ by using dry nitrogen as the effluent gas. Melting point readings were given in the form of exothermic or endothermic peak in the DSC thermograms $[10,11]$.

\section{Nanostructured lipid carrier formation}

The hot homogenization technique was selected for the formulation of NLC. Different concentrations of compritol (solid lipid) and softigen (liquid lipid) as shown in Table 1 were weighed and taken in a China dish to form a lipid matrix. These lipid phases were allowed to melt at $75{ }^{\circ} \mathrm{C}$, until it attains a uniform and clear liquid. In a beaker, prepare aqueous surfactant phase composing of various concentrations of span 80 and poloxamer 188 $(0.5 \% \mathrm{w} / \mathrm{v}$ in all formulations) as co-surfactant as shown in Table 1. The hot aqueous phase was then dropwise added to the oil phase geometrically and the mixture was homogenized for $15,000 \mathrm{rpm}$ by differing the homogenization time in minutes based on the formulation to form a hot preemulsion. It was subsequently homogenized at $75{ }^{\circ} \mathrm{C}$ using high-speed homogenizer to get NLC nanosuspension. The composition of the formulations is summarized in Table 1 [12-14].

\section{Optimization by Box-Behnken design}

Optimization of formulation and process variable in the NLC formulation was carried out using design expert software, which shows 17 formulation runs. BoxBehnken design (BBD) of response surface methodology with 17 formulation runs were used to examine the effects of changes in the independent variable over dependent variables as shown in Table 1 . In this design, the execution of first order response surface model and elucidation of the effect outcome was based on a $3^{3}$ factorial design with one replicate the model. The selected independent variables from optimization parameters are X1 (solid lipid: liquid lipid, i.e., compritol 888 ATO: softigen); X2 (homogenization speed 15,000 rpm with different time); X3 surfactant span 80 at three different levels coded as low $(-1)$, medium $(0)$, high $(+1)$ and their effect on dependent variables like Y1-particle size in $\mathrm{nm}, \mathrm{Y} 2$-zeta potential and Y3-entrapment efficiency of NLC was examined. From this design, a total of 17 formulation runs were generated by four center points and 12 factorial points [15-17].

\section{Characterization of nanostructured lipid carrier Particle Size, polydispersity index, and zeta potential}

The particle size, polydispersity index, and zeta potential of NLCs were determined by the Horiba nanoparticle size analyzer. It provides the mean particle size (PS in $\mathrm{nm}$ ), polydispersity index (PI), and zeta potential (ZP $\mathrm{mV}$ ) as a measure of the width of the distribution. The analysis was performed after diluting the NLC dispersion of 1:20 (v/v) in deionized double-distilled water, followed by membrane $(0.45 \mu \mathrm{m})$ filtration. The scattering intensity, i.e., 90 or $170^{\circ}$, is based on the viscosity of the medium. The particle size of NLC should be in the range of $10-500 \mathrm{~nm}$ and PI should be less than 0.3 , which indicates a unimodal size distribution. All measurements were performed in triplicate (n-3) [18].

\section{Scanning electron microscope studies}

The surface morphology of the NLCs for the selected optimized formulation F7 (simvastatin NLC) was observed by the scanning electron microscope. Lyophilized NLC powder samples were coated with platinum of 600 $\AA$ A by using a sputter coater and examined through scanning electron microscopy (SEM). Coated NLC was mounted on a sample holder and scanned through an electron beam. The electron beam was striking the NLC particles and emits secondary electrons based on the nature of the surface, which gives the surface morphology image of NLC. Compare the mean particle size of NLC obtained by SEM with NLC size obtained by the Horiba nanoparticle size analyzer $[19,20]$.

\section{Encapsulation efficiency}

Encapsulation Efficiency (EE\%) of drug in NLCs was determined by analyzing the free drug concentration by using the UV method. One millilieter of NLC nanodispersion which is equivalent to one formulation was placed in the dialysis bag. Then the dialysis membrane bag was placed in a centrifuge tube with $9 \mathrm{ml} \mathrm{pH} \mathrm{7.4}$ phosphate buffer saline (PBS) and using REMI centrifuge, it was centrifuged for $1 \mathrm{~h}$ at 15,000 rpm to extract the encapsulated drug from NLC carrier. Five milliliters of sample of PBS was taken and the drug concentration was determined by UV spectrophotometer at $238 \mathrm{~nm}$ against a blank solution that was prepared by using the same ingredients but without the drug. The analysis was made in triplicate $(n-3)$. EE\% was calculated by the following equation;

$$
E E \%=\frac{T s-T t X 100}{T s}
$$

where Ts is the total amount of simvastatin taken for formulation and $\mathrm{Tt}$ is the amount of simvastatin in $5 \mathrm{ml}$ saline [21].

\section{In-vitro drug release studies}

In-vitro drug release for NLC formulation was performed over $24 \mathrm{~h}$ using the dialysis membrane method. One milliliter of NLC formulation equivalent to $10 \mathrm{mg}$ 
Brits Raj et al. Future Journal of Pharmaceutical Sciences

(2019) 5:9

Page 4 of 14

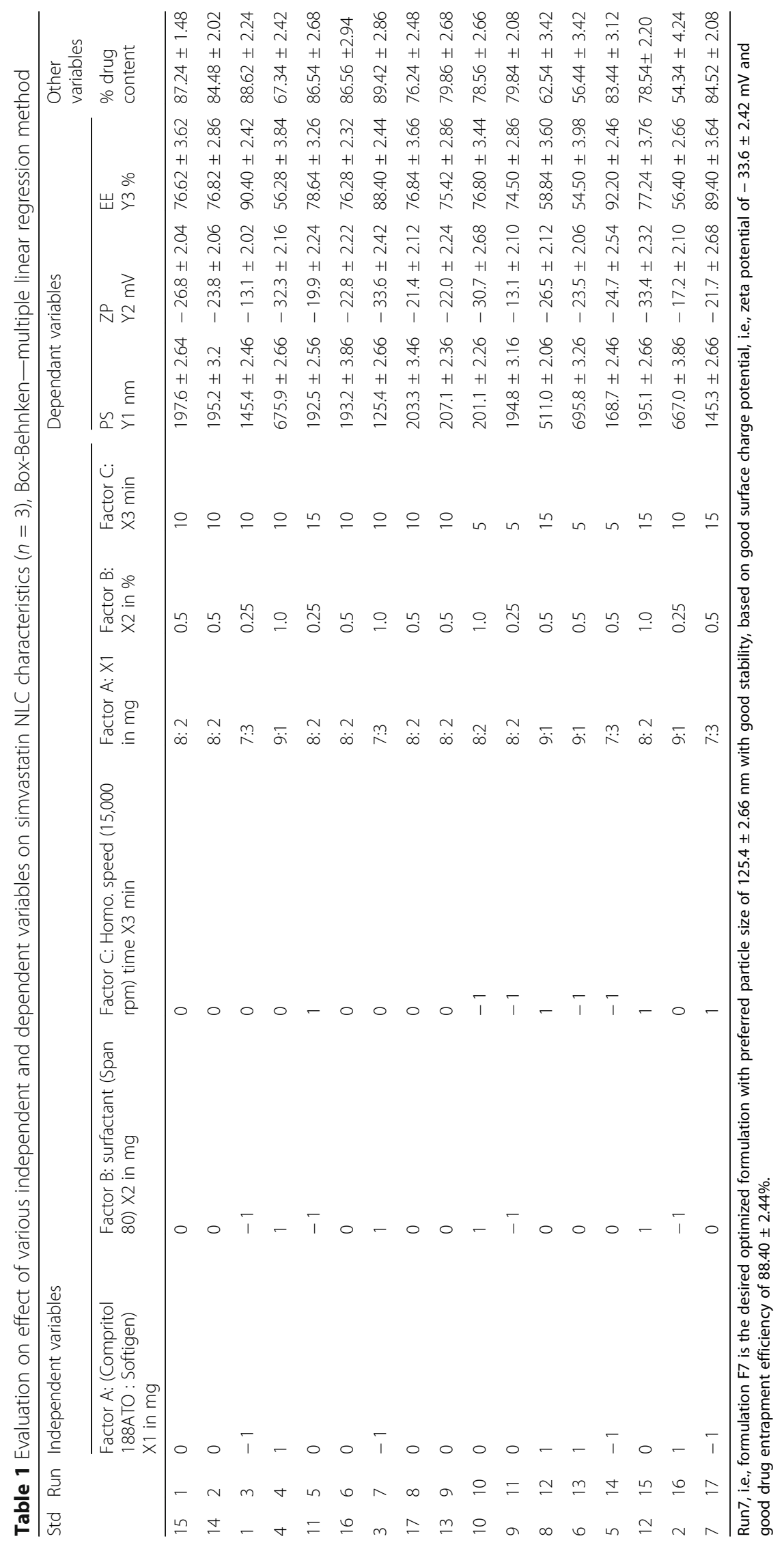


of the drug was taken in dialysis membrane and both the open ends of dialysis membrane were tied. The membrane was allowed to immerse in a $100 \mathrm{ml}$ phosphate buffer solution with $7.4 \mathrm{pH}$. The system was stirred continuously with magnetic stirrer at $100 \mathrm{rpm}$. The samples were collected at an interval of $0,1,2$, $4,8,12$, and $16 \mathrm{~h}$ and simvastatin content in the receptor compartment was determined by UV spectrophotometer at $238 \mathrm{~nm}$. Sink conditions were maintained in the receptor compartment during in-vitro release studies. The experiment was carried out in triplicate $(\mathrm{n}-3)[22,23]$.

\section{Formulation of transdermal patch}

NLC loaded transdermal patch was prepared by the solvent evaporation method. Four NLC loaded transdermal formulations was formulated by changing the concentration of polymer proportion PVP, PVA, and concentration of permeation enhancers DMSO as shown in Table 2. Weighed quantity of polymer was dispersed in $10 \mathrm{ml}$ of chloroform and stirred well in a magnetic stirrer at 1000 rpm until it gets a uniform translucent thickened solution. Then add the required volume of permeation enhancers and plasticizer polyethylene glycol (PEG). Continuously stir the above solution until it gets a uniform viscous solution. With the solution obtained, add NLC suspension equivalent to $10 \mathrm{mg}$ of the drug until it gets a uniformly dispersed solution. Then take a lubricated glass slide and keep it in a horizontally uniform substrate and pour the above solution uniformly in it. Care should be taken, i.e., air entrapment or avoid bubble formation and overflow of the solution. Allow the solvent to evaporate in room temperature, until it dries and remove the patch from the substrate and store it in a desiccator for further evaluation studies [24-26].

\section{Evaluation of transdermal patches Physical characteristics}

Thickness of the patches was measured using Vernier calipers at three different places, and then the mean value was calculated. Weight variation was studied as follows. Take the randomly selected ten different patches and weigh it individually. The average weight of the ten patches was calculated. The individual weight should not exceed beyond $\pm 5 \%$ compared to the average weight of patches. Out of ten patches, one patch can deviate from the desired patch. Such determination was performed for each formulation and the mean value was calculated. The folding endurance test will give the efficiency of elastic and brittle nature of the patch. It was determined by repeatedly folding the patches at the same place until it breaks. The number of times the film could be folded at the same place without breaking will give the folding endurance value [25].

\section{Drug content}

A prepared patch was taken and impregnated with 100 $\mathrm{ml}$ of phosphate buffer saline $(\mathrm{pH}$ 7.4) and kept for homogenization in a homogenizer for $24 \mathrm{~h}$. Then the contents were filtered, and simvastatin concentration was estimated from the filtrate by a UV spectrophotometer at $238 \mathrm{~nm}[26]$.

\section{Ex-vivo drug permeation study}

Ex-vivo skin permeation studies were performed by Franz diffusion cell with a receptor compartment capacity of $10 \mathrm{ml}$ and effective diffusion area of $2.5 \mathrm{~cm}^{2}$. Freshly excised albino Wistar rats' abdominal skin was mounted between the donor and receptor compartment of the diffusion cell with the stratum corneum side facing the donor compartment. The formulated patches were placed over the skin. For the ex-vivo permeation study, rat stratum corneum was equilibrated in Franz diffusion cells overnight for hydration. The receptor compartment of the diffusion cell was filled with phosphate buffer saline $\mathrm{pH} 7.4$ and its temperature was maintained at $37 \pm 1{ }^{\circ} \mathrm{C}$ by circulating water bath in order to ensure that the surface membrane temperature was $37 \pm 1{ }^{\circ} \mathrm{C}$. The whole assembly was fixed on a magnetic stirrer, and the solution in the receptor compartment was constant and continuously stirred using magnetic beads at $100 \mathrm{rpm}$; the temperature was maintained at $37 \pm 0.5{ }^{\circ} \mathrm{C}$. The sample with $0.5 \mathrm{ml}$ of solution were withdrawn at pre-determined time intervals $(2,4$,

Table 2 Coefficient table for effect of independent variable on dependent variable

\begin{tabular}{lllllllllll}
\hline Response & Intercept & $A$ & $B$ & $C$ & $A B$ & $A C$ & $B C$ & $A^{2}$ & $B^{2}$ & $C^{2}$ \\
\hline PS & 199.28 & 245.612 & -0.2625 & -27.05 & 7.2 & -40.375 & -0.925 & 194.235 & 9.885 & -13.29 \\
$\mathrm{P}=$ & & $<0.0001$ & 0.9842 & 0.0728 & 0.7031 & 0.0612 & 0.9607 & $<0.0001$ & 0.5933 & 0.4765 \\
$\mathrm{ZP}$ & -23.36 & -0.8 & -8.3375 & -1.1875 & 1.35 & -1.5 & -1.025 & -0.2575 & -0.4325 & -0.4825 \\
$\mathrm{P}=$ & & 0.3245 & $<0.0001$ & 0.1598 & 0.2466 & 0.2029 & 0.3691 & 0.8117 & 0.6902 & 0.6570 \\
$\mathrm{EE}$ & \multirow{2}{*}{$\mathrm{N} .396$} & -16.7975 & -0.1525 & 0.765 & 0.47 & 1.785 & -0.925 & -3.293 & -0.233 & 0.632 \\
$\mathrm{P}=$ & & $<0.0001$ & 0.5976 & 0.0276 & 0.2674 & 0.0026 & 0.0495 & $<0.0001$ & 0.5594 & 0.1404 \\
\hline
\end{tabular}

$A=$ lipid concentration, $B=$ surfactant concentration, $C=$ homogenization time 
$6,8,16,24$, and $48 \mathrm{~h}$ ) and replaced with an equal quantity of PBS into the receptor compartment. All samples were analyzed for simvastatin content by HPLC method [27-29].

\section{In-vivo pharmacokinetic} In-vivo pharmacokinetic studies

The pharmacokinetic (PK) performance of NLC following oral and transdermal administration was studied by using PK solver software. Healthy male adult albino Wistar rats weighing between 180 and $250 \mathrm{~g}$ were used. A single dose study in four groups comprising of six animals in each has been divided as follows.

\begin{tabular}{ll}
\hline $\begin{array}{l}\text { Standard } \\
\text { group }\end{array}$ & $\begin{array}{l}\text { Marketed available simvastatin (ZOCOR } 10 \mathrm{mg} / \mathrm{kg} \text { ) with } \\
\text { CMC p.o. }\end{array}$ \\
Test Group I & Simvastatin NLC suspension (10 mg/kg) p.o. \\
Test Group II & $\begin{array}{l}\text { Simvastatin loaded transdermal patch (single patch } \\
\text { equivalent to } 10 \mathrm{mg} / \mathrm{kg} \text { ) through skin administration }\end{array}$ \\
Test Group III & $\begin{array}{l}\text { Simvastatin NLC loaded transdermal patch (single patch } \\
\text { equivalent to } 10 \mathrm{mg} / \mathrm{kg} \text { ) through skin administration }\end{array}$ \\
\hline
\end{tabular}

Animals were fasted $24 \mathrm{~h}$ prior to the administration of drug formulations, but had free access to water. One day prior to the experiment, hair on the abdominal area was clipped by applying a depilatory agent for $10 \mathrm{~min}$ and washed with distilled water. On the day of the experiment, the animals were anaesthetized with ketamine $(10 \mathrm{~m} / \mathrm{kg}$, i.p), and they were secured in a supine position. The transdermal patch $\left(2.5 \mathrm{~cm}^{2}\right)$ was applied on the hair-free abdominal skin with a pressuresensitive adhesive and occluded with plaster. Drug solution was administered orally $(10 \mathrm{mg} / \mathrm{kg})$ with a help of oral feeding needle. Blood samples volume of about 0.5 $\mathrm{ml}$ were collected at $0.5,2,4,8,12,24$, and $48 \mathrm{~h}$ time interval, after oral and transdermal administration by a retro-orbital puncture. The samples were collected with the help of capillary tubes from retro orbital puncture into a heparinized glass tube containing anticoagulant ammonium oxalate ( $1 \%$ solution). The plasma was separated immediately with the help of microcentrifugation at $5000 \mathrm{rpm}$ and stored at $-20{ }^{\circ} \mathrm{C}$ until the analysis done in HPLC $[26,30]$.

\section{Sample preparation from simvastatin plasma drug concentration}

About $1.5 \mathrm{ml}$ of treated animal blood was subjected to centrifugation at $5000 \mathrm{rpm}$ for $5 \mathrm{~min}$ and $0.75 \mathrm{ml}$ of plasma was collected into Eppendorf tube. To this sample, add $0.5 \mathrm{ml}$ of $10 \%$ trichloroacetic acid. Extract the drug from plasma by centrifugation at $4000 \mathrm{rpm}$ for $15 \mathrm{~min}$ at $4{ }^{\circ} \mathrm{C}$. The supernatant solution was siphoned out and injected into the HPLC to quantify the simvastatin present in the plasma extracted sample as follows.

\section{Quantification of simvastatin in plasma}

Quantification of simvastatin in plasma was carried out using HPLC method.

Column: reversed-phase C18 column $(250 \mathrm{~mm} \times 4.6$ $\mathrm{mm}$ i.d., particle size $-5 \mu \mathrm{m}$ )

Mobile phase: methanol: $2 \mathrm{mM}$ ammonium acetate and $500 \mu \mathrm{l}$ of $0.5 \%$ formic acid $(80: 20, \mathrm{v} / \mathrm{v})$

Flow rate: $1.0 \mathrm{ml} / \mathrm{min}$

Injection volume: $5 \mu \mathrm{l}$

Calibration curve (concentration in $\mu \mathrm{g} / \mathrm{ml}$ on $X$-axis vs. peak area in $\%$ on $Y$-axis) was obtained for eight solutions of simvastatin by using trichloroacetic acid solution in the concentration ranging from 0.02 to 0.16 $\mu \mathrm{g} / \mathrm{ml}$ which was determined at $238 \mathrm{~nm}$ and the regression value was found to be $r^{2}=0.999$. The unknown plasma drug concentration was determined by picking the unknown sample peak area and interpolated it to $X$-axis at each time interval [31-37].

\section{Pharmacokinetic data analysis}

The time vs. plasma drug concentration data are derived from HPLC method and are plotted in PK solver software. From the individual plasma drug concentration versus time profile, the following parameters are determined like peak plasma concentration $\left(C_{\max }\right)$, time taken to attain peak plasma concentration $\left(t_{\max }\right)$, area under curve $\left(\mathrm{AUC}_{0-\mathrm{t}}\right)$, and $\left(\mathrm{AUC}_{0-\infty}\right)$ were read directly. The other PK parameters like biological half-life $\left(t_{1 / 2}\right)$ and mean residence time (MRT) were also calculated using PK solver software [30-37].

\section{Results and discussion}

\section{Preformulation studies}

Drug and excipients compatibility study was performed by FTIR. Figure 1a shows an FTIR spectrum of simvastatin drug, Figure 1b shows a FTIR spectrum of simvastatin NLC suspension, and Figure 1c shows a FTIR spectrum of simvastatin NLC loaded transdermal patch. From which we can conclude that preferred functional group frequencies are reproducible in NLC and transdermal patch when compared to the standard drug. Especially reproducible main functional groups wave numbers like $-\mathrm{OH}$ stretching as $3551.55 \mathrm{~cm}^{-1}$, $2966.58 \mathrm{~cm}^{-1}, 2872.80 \mathrm{~cm}^{-1},-\mathrm{C}=\mathrm{O}$ stretching as 1723.73 $\mathrm{cm}^{-1}$, -C-O stretching as $1118.85 \mathrm{~cm}^{-1},-\mathrm{C}-\mathrm{H}$ bending as $990.20 \mathrm{~cm}^{-1}$ in pure drug; $-\mathrm{OH}$ stretching as $3340 \mathrm{~cm}^{-1}$, $2944.50 \mathrm{~cm}^{-1}, 2832.87 \mathrm{~cm}^{-1}$, -C-O stretching 1251.09 $\mathrm{cm}^{-1}, 1081.79 \mathrm{~cm}^{-1}$ in NLC; $-\mathrm{OH}$ stretching as 3648.38 $\mathrm{cm}^{-1}, 2922.12 \mathrm{~cm}^{-1}, 2853.69 \mathrm{~cm}^{-1},-\mathrm{C}=\mathrm{O}$ stretching as $1732.87 \mathrm{~cm}^{-1}$, $-\mathrm{C}-\mathrm{H}$ bending as $930.75 \mathrm{~cm}^{-1}$ in transdermal patch respectively. Some of the functional 


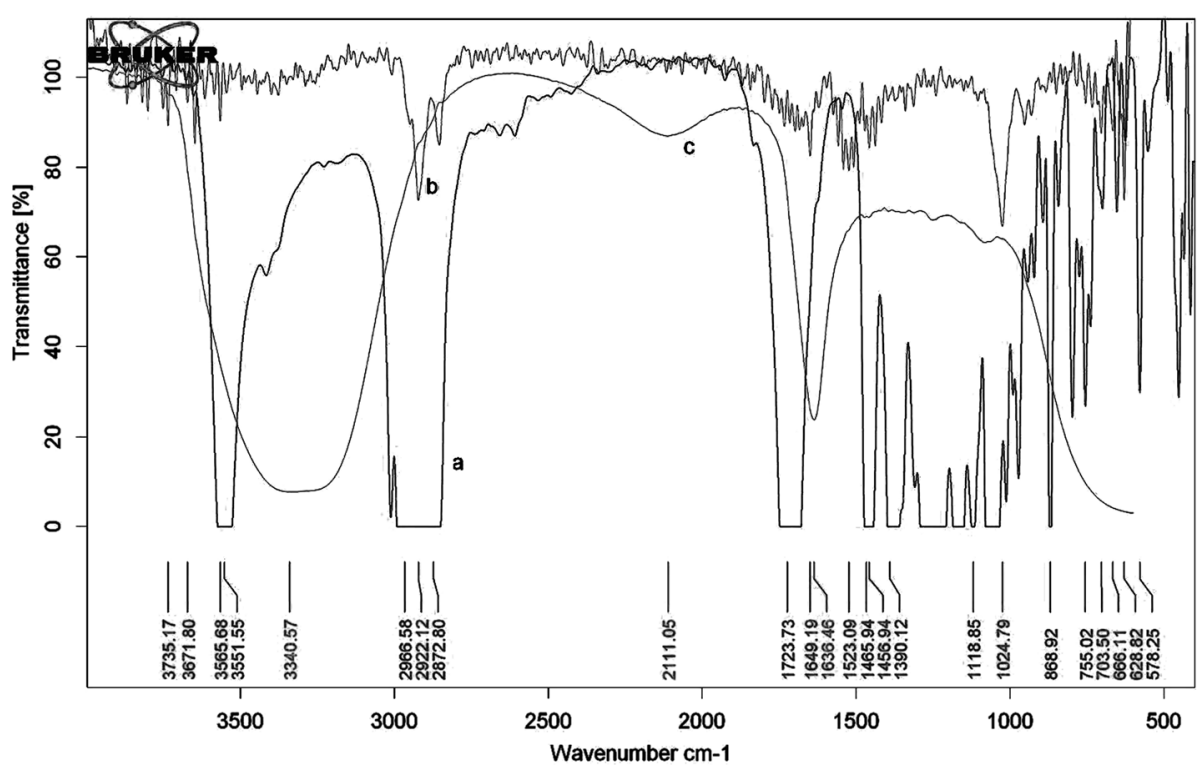

Fig. 1 FT-IR spectra. a Simvastatin. b Simvastatin nanostructured lipid carrier formulation. c Simvastatin nanostructured lipid carrier loaded transdermal patch

groups are overlapped may be due to the effect of encapsulation of lipid over simvastatin.

The DSC studies reveal the polymeric effect, i.e., encapsulation effect of lipid on a drug based on the changes in melting point peak values, i.e., for pure drug it shows an endothermic peak at $142.36{ }^{\circ} \mathrm{C}$ and for bound drug it shows a peak at $75.50{ }^{\circ} \mathrm{C}$ which was correlated with the lipid melting point peak at $76.60{ }^{\circ} \mathrm{C}$ as shown in Fig. 2.

\section{Optimization of hot homogenization technique for preparation of NLC}

Optimization of formulation technique was carried out by Box-Behenken Design ( $3^{3}$ factorial design) by using polynomial quadratic model and multiple linear regression method as shown in Table 1 and Figs. 3 and 4. Table 2 shows the coefficient table which discussed about the effect of the independent variable on the dependent variable. From the data, it shows that a strong correlation was observed between lipid concentration and particle size with $r^{2}=0.902$. It shows that there was an increase in particle size to increase in concentration of lipid. On executing with analysis of variance (ANOVA), it shows $p<0.0001$, which confirms that there is a significant difference in PS in increasing the concentration of lipid. Increase in surfactant concentration was found to shift the zeta potential of NLC to stable condition on its phase, so that maximum particle conductivity was achieved. It confirms that the desired surface charge potential will keep the particle in motion without sedimentation. Further increase in surfactant after 0 level, there is no change in zeta potential $\left(r^{2}=-\right.$ 0.942 negative linear regression). It may be due to the effect of further increase in lipid concentration, so that the surfactant effect on variables was masked by lipid effect. By establishing it in ANOVA $p<0.0001$, there was a significant change in $\mathrm{ZP}$ proportional to the increase in surfactant concentration. The relation between surfactant concentration and particle size shows no regression correlation values. When there is a decrease in PS from -1 to 0 levels, there is an increase in PS from 0 to 1 level; this may be due to increase in lipid concentration which masks the effect of surfactant effect. Increase in surfactant concentration and homogenization time shows simultaneous increases in the \%EE. From the optimization data, it was concluded that F7 was found to be the optimized simvastatin-loaded NLC formulation for further studies. The polynomial equation that was derived from the coefficient table from Box-Behnken design which was produced from the response factors, confirms that the change in independent variables is responsible for change in dependent variables as follows.

$$
\begin{aligned}
\mathrm{PS}= & 199.28+245.612 A+194.235 A^{2} \\
\mathrm{EE}= & 76.396-16.7975 A+0.765 \mathrm{C} \\
& +1.785 A C-0.925 B C-3.293 A^{2}
\end{aligned}
$$

$\mathrm{ZP}=-23.36-8.3375 B$ 


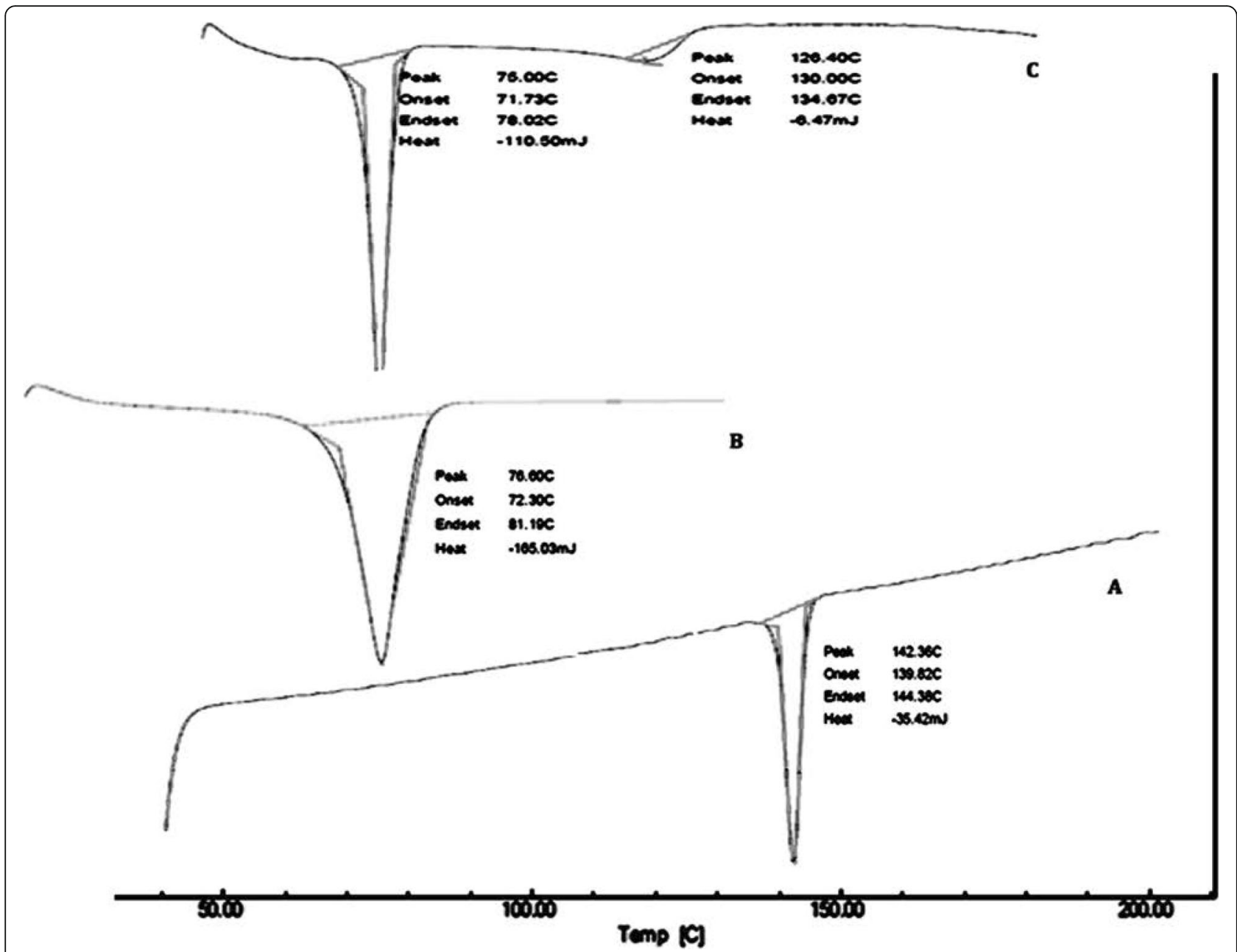

Fig. 2 DSC thermograms. a Simvastatin drug. b Simvastatin nanostructured lipid carrier formulation. c Compritol lipid

where $A$ is the lipid concentration, $B$ is surfactant concentration, and $C$ is the homogenization time.

\section{Evaluation of nanostructured lipid carrier formulation}

Various evaluation studies were carried out for NLC formulation and tabulated in Table 1. The PS for optimized F7 formulation was found to be $125.4 \pm 2.66$ $\mathrm{nm}, \mathrm{ZP}$ was found to be $-33.6 \pm 2.42 \mathrm{mV}$, and PI as $0.480 \pm 0.002$. The optimized formulation was analyzed by scanning electron microscopy (SEM) studies as shown in Fig. 5. In which Fig 5a shows enlarged SEM photograph of NLC and Fig. 5b shows group of NLC which linked like a block. It will enhance the drug loading efficiency and penetration of drug through the physiological barriers. The F7 formulation shows maximum drug content of about $89.42 \pm 2.86 \%$, which may be due to more entrapment efficiency of drug into NLC of around $88.40 \pm 2.44 \%$ and from this it can also confirm that the concentration of the drug was uniformly distributed throughout the nanoparticle. Invitro drug release studies for F7 formulation shows better control of drug release as $98.62 \pm 3.800 \%$ in $24 \mathrm{~h}$ than marketed Zocor tablet as shown as in Fig. 6. From this release data, it is concluded that the cumulative amount of drug release is obtained in a controlled manner from NLC carrier.

\section{Evaluation of NLC loaded transdermal patch}

The F7 NLC loaded transdermal patch was formulated by solvent evaporation method and the physical characteristics like weight variation, thickness, folding endurance, and \% moisture content were evaluated. The release characteristics like \% drug content, ex-vivo drug permeation studies, and in-vitro drug release kinetics studies were evaluated and tabulated in Table 3 . The individual patch weight for all the formulation has no 


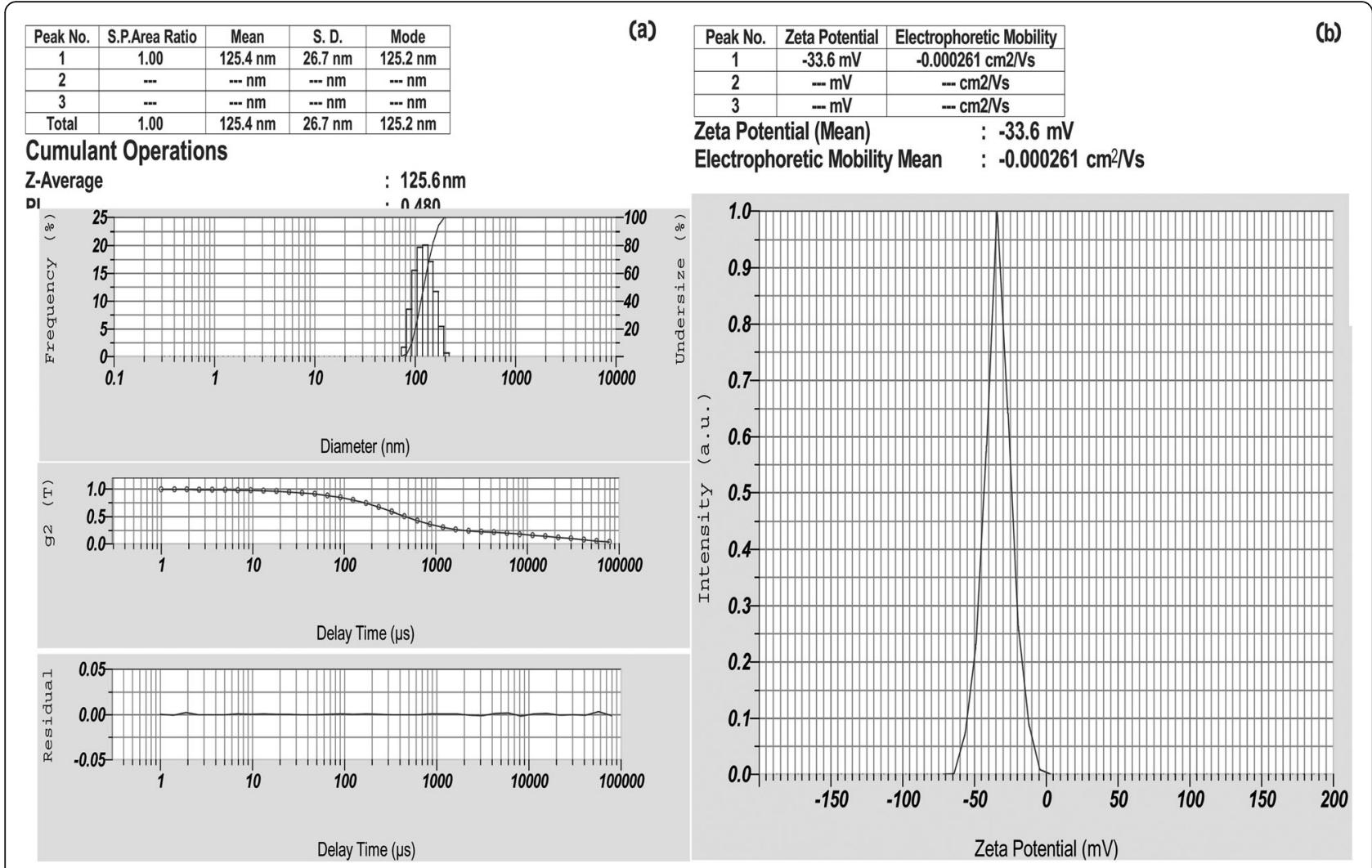

Fig. 3 a Particle size; polydispersity index of F7 nanostructured lipid carrier formulation. b Zeta potential of F7 nanostructured lipid carrier formulation

deviation from average weight. When measuring the patch thickness in three different places, it showed uniformity of thickness all over the patch, which implies good flatness of patch and also it confirms there is no accumulation of polymer content at a particular place alone. Formulation ST4 shows good folding endurance of 120-130 when compared to all the other patches which reflect the desired concentration of plasticizer. The moisture content for all the formulation is $<1 \%$, which shows that there is no interaction of moisture in the patch and it has good stability of storage and also it will be away from microbial contamination. The percentage drug content of ST4 formulation was found to be $90.80 \pm 0.54 \%$, which says that by increasing the concentration of polymer proportion, the NLC entrapment in patch also increases.

The ex-vivo drug permeation studies through rat skin for the optimized NLC formulation F7 loaded transdermal patch formulation (ST1-ST4) was carried out in $7.4 \mathrm{pH}$ phosphate buffer by using Franz diffusion cell. The percentage amount of drug permeated through rat skin was found to be $94.54 \pm 2.04 \%$ to $98.24 \pm 2.58 \%$ in $48 \mathrm{~h}$ as shown in Table 3 and Fig.
6. From the results, it was observed that ST4 NLC transdermal patch shows better control of drug release with good permeation index. In general, the drug release from ST4 formulation showed a predetermined controlled release, which obeys zero order drug release pattern. The in-vitro release kinetics of simvastatin-loaded NLC transdermal patches are evaluated by fitting the drug release data into various kinetic models like first-order, zero-order, Higuchi, Hixson Crowell, and Peppas equations. The drug release kinetic data for optimized NLCs formulation ST4 obey the zero-order models through the regression $r^{2}$ values, which was found to be 0.994 respectively with good regression and obeys the linearity. So it is confirmed that the NLC loaded transdermal patch formulation (ST4) follow zero-order kinetics, which release the same amount of drug at unit time interval in a controlled and predetermined manner. It is an ideal formulation for release of drug to achieve desired pharmacological action with reduced side effects. When fitting the drug release pattern to Higuchi, it shows the regression $r^{2}$ value as 0.965 , which confirm that the drug release pattern from patch 


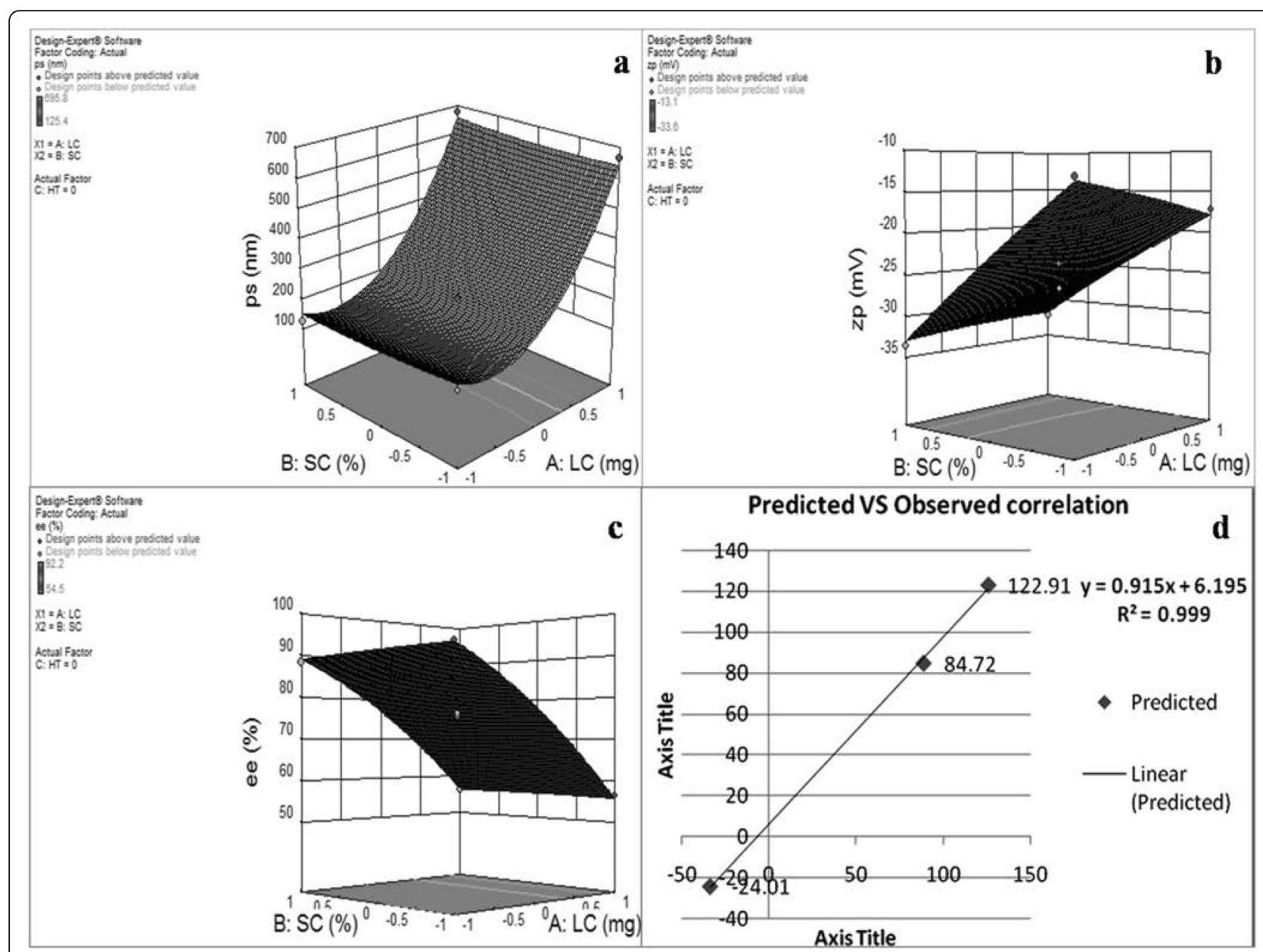

Fig. 4 Effect of independent variables like lipid concentration, surfactant concentration on dependent variable like a particle size, b zeta potential, c entrapment efficiency, and $\mathbf{d}$ predicted vs. observed value correlation

obeys diffusion. From the Peppas equation fittings, the release exponent value $(n)$ for ST4 formulation was found to be 0.803 which lies within the range of $n=0.5-1$; it implies that the release of drug from NLC obeys non-Fickian diffusion mechanism.

\section{In-vivo pharmacokinetic studies}

To determine the unknown plasma drug concentration, a calibration curve was designed by using different concentration of simvastatin. The linearity of calibration curve was determined by plotting the peak area and nominal concentration of simvastatin. The linearity studies are performed from eight different concentrations of simvastatin were analyzed $(0.02,0.04,0.06,0.08,0.1$, $0.12,0.14,0.16 \mu \mathrm{g} / \mathrm{ml})$. The peak area response was linear over the concentration range studied. The coefficient of correlation ' $r$ ' was found to be 0.999 .
The HPLC method by interpolation technique has been successfully used to determine the pharmacokinetic data from unknown plasma drug concentration followed by a single-dose administration of simvastatin (ZOCOR), simvastatin NLC, simvastatin transdermal patch, and simvastatin NLC transdermal patch. The unknown concentration was determined by using a calibration curve. The mean plasma concentration of simvastatin as a function of time has been plotted and the comparative pharmacokinetic parameters on in-vivo plasma drug concentration profile between the marketed simvastatin tablet (ZOCOR), simvastatin nanostructured lipid carrier, simvastatin-loaded transdermal patch, and simvastatin nanostructured lipid carrier loaded transdermal patch was tabulated in Table 4. It was observed that simvastatin NLC loaded transdermal patch controlled the release as well as pharmacokinetic parameters when compared to other formulations as shown in Table 4. There was a 


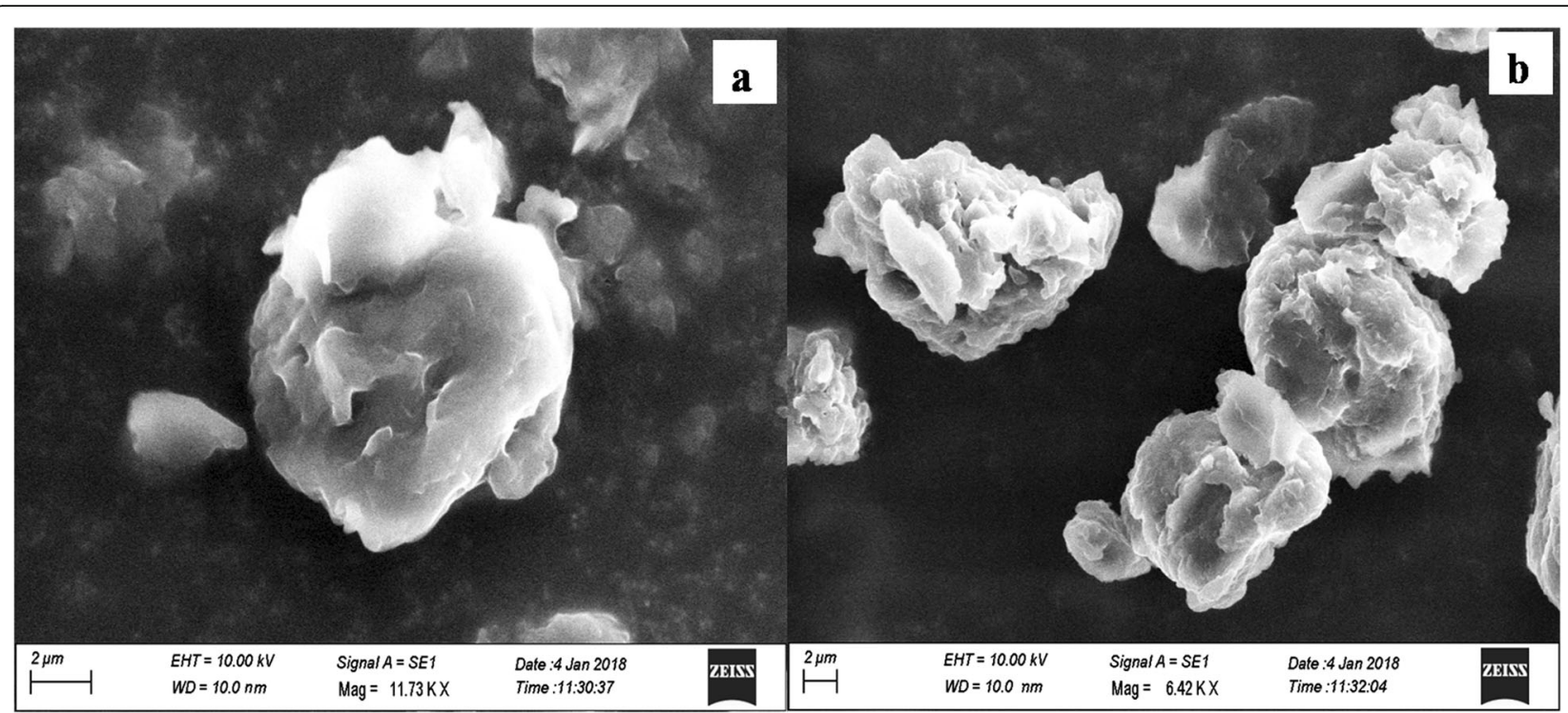

Fig. 5 SEM photograph of nanostructured lipid carrier formulation. a Enlarged SEM photograph of nanostructured lipid carrier. b Group of nanostructured lipid carrier SEM photograph, which linked like a blocks

significant difference with $p<0.05$ between the pharmacokinetic parameters of marketed simvastatin, NLC simvastatin, simvastatin-loaded transdermal patch, and simvastatin NLC loaded transdermal patch with $T_{\max }$ of 2 $\mathrm{h}, 8 \mathrm{~h}, 9.5 \mathrm{~h}$, and $12 \mathrm{~h}$; and the maximum peak plasma concentration $\left(C_{\max }\right)$ of $0.1410 \mu \mathrm{g} / \mathrm{ml}, 0.1148 \mu \mathrm{g} / \mathrm{ml}, 0.086$ $\mu \mathrm{g} / \mathrm{ml}$, and $0.065 \mu \mathrm{g} / \mathrm{ml}$ respectively. Area under curve
$\left(\mathrm{AUC}_{0-\alpha}\right)$ was found to be $8.8695 \mu \mathrm{g} / \mathrm{ml} \mathrm{h}, 84.8520 \mu \mathrm{g} / \mathrm{ml}$ h, $132.5082 \mu \mathrm{g} / \mathrm{ml} \mathrm{h}, 163.0397 \mu \mathrm{g} / \mathrm{ml} \mathrm{h}$; mean residence time (MRT) of drug $\mathrm{MRT}_{0-\alpha}$ was found to be $11 \mathrm{~h}, 23 \mathrm{~h}$, $38 \mathrm{~h}$, and $44 \mathrm{~h}$ respectively. From the in-vivo pharmacokinetics data, it was concluded that an increase in AUC ${ }_{0-\infty}, T_{\max }$, MRT with decrease in $C_{\max }$ in NLC loaded transdermal formulation when compared to all other test

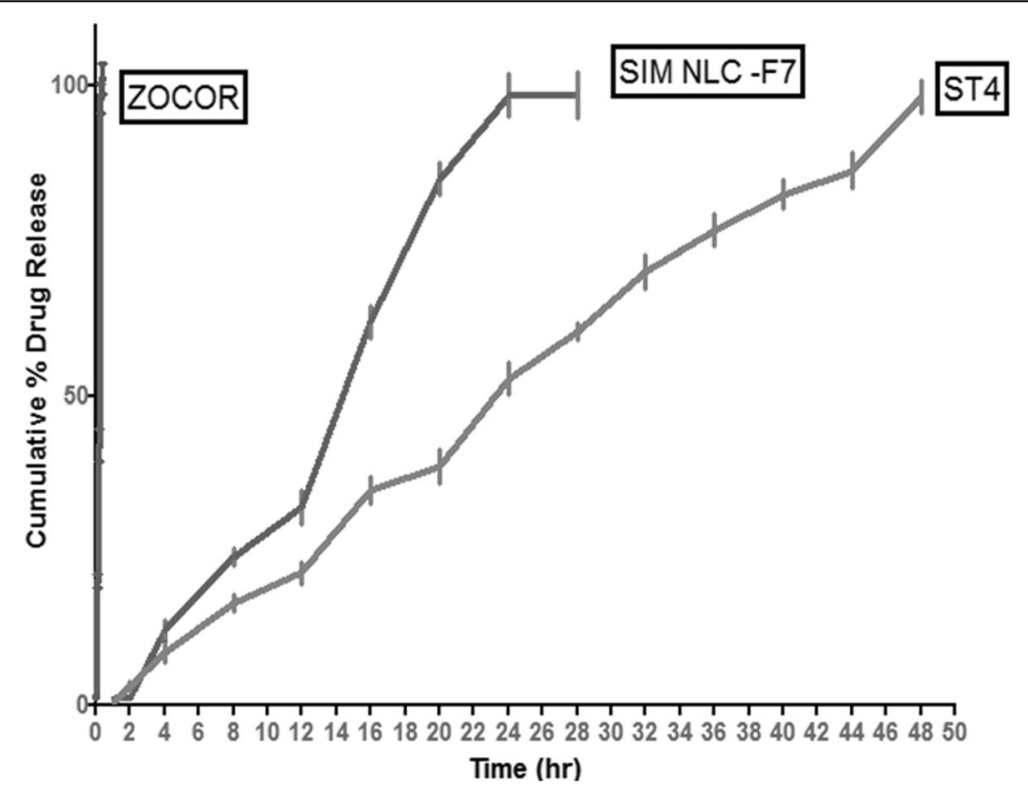

Fig. 6 Comparative drug release studies between marketed simvastatin tablet (ZOCOR), simvastatin nanostructured lipid carrier, and simvastatin nanostructured lipid carrier loaded transdermal patch (mean $\pm \mathrm{SD}, n=3$ ) 
Table 3 Formulation and evaluation of simvastatin NLC loaded transdermal patches (mean $\pm \mathrm{SD}, n=3$ )

\begin{tabular}{|c|c|c|c|c|}
\hline Ingredients & ST1 & ST2 & ST3 & ST4 \\
\hline Simvastatin NLC F7 & Eq. to $10 \mathrm{mg}$ & Eq. to $10 \mathrm{mg}$ & Eq. to $10 \mathrm{mg}$ & Eq. to $10 \mathrm{mg}$ \\
\hline Poly vinyl alcohol (PVA) & $2.5 \mathrm{mg}$ & $5.0 \mathrm{mg}$ & $7.5 \mathrm{mg}$ & $10 \mathrm{mg}$ \\
\hline Polyvinyl pyrrolidone (PVP) & $2.5 \mathrm{mg}$ & $2.5 \mathrm{mg}$ & $2.5 \mathrm{mg}$ & $2.5 \mathrm{mg}$ \\
\hline Dimethyl sulfoxide (DMSO) & $0.015 \mathrm{ml}$ & $0.175 \mathrm{ml}$ & $0.020 \mathrm{ml}$ & $0.0225 \mathrm{ml}$ \\
\hline Propylene glycol (PG) & $0.015 \mathrm{ml}$ & $0.175 \mathrm{ml}$ & $0.020 \mathrm{ml}$ & $0.0225 \mathrm{ml}$ \\
\hline \multicolumn{5}{|c|}{ Evaluation parameters-transdermal patches } \\
\hline Weight variation (g) & $0.074 \pm 0.002$ & $0.082 \pm 0.001$ & $0.080 \pm 0.003$ & $0.076 \pm 0.002$ \\
\hline Thickness (mm) & $0.94 \pm 0.06$ & $0.92 \pm 0.22$ & $0.90 \pm 0.08$ & $0.94 \pm 0.10$ \\
\hline Folding endurance & $75-80$ & 90-100 & $105-115$ & $120-130$ \\
\hline Moisture content \% & $0.68 \pm 0.02$ & $0.64 \pm 0.04$ & $0.52 \pm 0.06$ & $0.54 \pm 0.06$ \\
\hline Drug content \% & $86.54 \pm 0.28$ & $84.42 \pm 0.24$ & $82.20 \pm 0.42$ & $90.80 \pm 0.54$ \\
\hline Ex-vivo skin permeation studies $48 \mathrm{~h}$ & $96.48 \pm 2.40$ & $97.64 \pm 3.86$ & $98.24 \pm 2.58$ & $94.54 \pm 2.04$ \\
\hline \multicolumn{5}{|l|}{ In-vitro release kinetic studies } \\
\hline Zero order $\left(r^{2}\right)$ & 0.945 & 0.9824 & 0.9977 & 0.994 \\
\hline First order $\left(r^{2}\right)$ & 0.742 & 0.730 & 0.696 & 0.658 \\
\hline Higuchi model $\left(r^{2}\right)$ & 0.936 & 0.947 & 0.954 & 0.965 \\
\hline Hixson Crowell model $\left(r^{2}\right)$ & 0.899 & 0.887 & 0.836 & 0.786 \\
\hline Korsmeyer Peppas model $\left(r^{2}\right)$ & 0.980 & 0.976 & 0.961 & 0.941 \\
\hline Korsmeyer Peppas model (n) & 0.702 & 0.752 & 0.711 & 0.803 \\
\hline
\end{tabular}

groups. In calculating the relative bioavailability by keeping marketed formulation as standard, it has been confirmed that NLC loaded transdermal patch shows enhancement of bioavailability of about $18.40 \%$ than other test formulations.

\section{Conclusion}

From the research data, it was concluded that newly upgraded hot homogenization method by choosing independent and dependent variables was an optimized and reproducible method for the formulation of NLC. The selected NLC formulation has been fabricated into transdermal patches and data are shown with desired results. From the in-vivo pharmacokinetic and pharmacodynamic data, it was concluded that the simvastatin NLC packed transdermal patch shows better bioavailability by enhancing the AUC in plasma drug concentration profile. It also ensures that NLC loaded transdermal patch attains an enhanced bioavailability of about $18.40 \%$ for simvastatin with desired therapeutic effect. Thus, it was concluded that the NLC transdermal patch will be a promising drug delivery system for poorly soluble and bioavailable drugs like simvastatin.

Table 4 Comparative in vivo pharmacokinetic studies data between treatment groups

\begin{tabular}{|c|c|c|c|c|}
\hline \multirow[t]{2}{*}{ Parameter } & \multirow{2}{*}{$\begin{array}{l}\text { Standard group } \\
\text { ZOCOR tablet ( } 10 \mathrm{mg} / \mathrm{kg} \text { )-oral } \\
\text { administration (marketed simvastatin } \\
\text { formulation) }\end{array}$} & \multirow{2}{*}{$\begin{array}{l}\text { Test group I } \\
\text { Simvastatin Nlc Suspension } \\
(10 \mathrm{mg} / \mathrm{kg}) \text {-oral } \\
\text { administration }\end{array}$} & \multirow{2}{*}{$\begin{array}{l}\text { Test group II } \\
\text { Simvastatin loaded transdermal } \\
\text { patch }(10 \mathrm{mg} / \mathrm{kg}) \text {-transdermal } \\
\text { route }\end{array}$} & \multirow{2}{*}{$\begin{array}{l}\text { Test group III } \\
\text { NLC loaded transdermal } \\
\text { patch }(10 \mathrm{mg} / \mathrm{kg})- \\
\text { transdermal route }\end{array}$} \\
\hline & & & & \\
\hline$T_{\max }(\mathrm{h})$ & 2 & 8 & 9.5 & 12 \\
\hline$C_{\max }(\mu \mathrm{g} / \mathrm{ml})$ & 0.1410 & 0.1148 & 0.086 & 0.065 \\
\hline $\mathrm{AUC}_{0-a}(\mu \mathrm{g} / \mathrm{ml} \mathrm{h})$ & 8.8695 & 84.8520 & 132.5082 & 163.0397 \\
\hline$M R T_{0-a}(h)$ & 11 & 23 & 38 & 44 \\
\hline \multicolumn{2}{|c|}{ F rel $=\frac{(\text { AUC })_{\text {test }} \cdot(\text { Dose })_{\text {std }}}{\left(\text { AUC }_{\text {test }} \cdot(\text { Dose })_{\text {test }}\right.}$} & $\begin{array}{l}\text { Bioavailability enhanced by } \\
9.64 \%\end{array}$ & $\begin{array}{l}\text { Bioavailability enhanced by } \\
14.95 \%\end{array}$ & $\begin{array}{l}\text { Bioavailability enhanced by } \\
18.40 \%\end{array}$ \\
\hline
\end{tabular}

Increase in $\mathrm{AUC}_{0-\infty} ; \mathrm{MRT} ; T_{\text {maxi }}$ decrease in Cmax in NLC loaded transdermal patch shows better bioavailability than other two dosage form 


\section{Abbreviation}

ANOVA: Analysis of variance; $\mathrm{AUC}_{0-a}$ : Area under curve; $\mathrm{C}_{\max }$ : Maximum peak plasma concentration; EE: Entrapment efficiency; HDL: High-density lipoprotein; LDL: Low-density lipoprotein; MRT: Mean residence time; NCL: Nanostructured lipid carrier; PDI: Polydispersity index; PS: Particle size; SEM: Scanning electron microscopy; TG: Triglycerides; ZP: Zeta potential

\section{Acknowledgments}

Authors also very much thankful to Dr. R. Venkataswamy, Chairman and Mr. R.V. Srinivas, Vice Chairman, Sri Venkateswara college of Pharmacy, RVS Nagar, Chittoor, Andhra Pradesh for providing the facilities for pursuing and successfully completing this research work. The authors thank Gatte Fosse Sas Saint-Press Cedex-France; Cremer Oleo GmbH \&Co. KG; Sisco research laboratories pvt.Itd-Maharashtra for providing the lipids and surfactants as gift samples to perform this project successfully.

\section{Authors' contributions}

SBR carried out the study designs for the formulation and evaluation of NLC. KBC conceived of the study and participated in drafting of manuscript. KBR participated in in vivo studies and performed this statistical analysis. All authors have read and approved the manuscript

\section{Funding}

This project was financially supported by the Department of Science and Technnology, New Delhi, India.

\section{Availability of data and materials}

Data are collected from PK solver (PharmPK); Design Expert 9 Software (Statease, Inc. USA); Graph pad Prism (Version 7 software, USA).

\section{Ethics approval}

In this study, all the procedures using albino Wistar rats, weighed 180-250 g, male, 6-8 weeks of age, were provided by the Institutional Animal Ethical Committee of Sri Venkateswara College of Pharmacy, Chittoor, India and approved with certificates of conformity: SVCOP/IAEC/004/2016-17. All animal procedures were approved by the Animal Ethics Committee of Sri Venkateswara College of Pharmacy.

\section{Consent for publication}

The corresponding author has taken authorized consent from all the authors. All the authors read the manuscript thoroughly and given consent for publication.

\section{Competing interests}

The authors acknowledge the financial support from the department of Science and Technology (DST) for this project (DST No: SB/F TP/ETA-02772013 dated 27.03.2012).

\section{Author details}

'Department of Pharmaceutics, Centre for Pharmaceutical Nanotechnology, Sri Venkateswara College of Pharmacy, RVS Nagar, Chittoor, Andhra Pradesh,

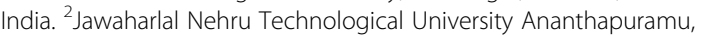
Anantapur, Andhra Pradesh, India.

\section{Received: 10 July 2019 Accepted: 1 October 2019}

\section{Published online: 05 December 2019}

\section{References}

1. Muchow M, Maincent P, Muller RH (2008) Lipid nanoparticles with a solid matrix (SLN, NLC, LDC) for oral drug delivery. Drug Dev Ind Pharm 34:13941405. https://doi.org/10.1080/03639040802130061

2. Li X, Nie SF, Kong J (2008). A controlled-release ocular delivery system for ibuprofen based on nanostructured lipid carriers. Int J Pharm 363:177-182. https://doi.org/10.1016/j.ijpharm.2008.07.017. Epub 2008 Jul 26.

3. Muller RH, Mader K, Gohla S (2000) Solid lipid nanoparticles (SLN) for controlled drug delivery - a review of the state of the art. Eur J Pharm Biopharm 50:161-177 https://doi.org/10.13040/IJPSR.0975-8232.1(12).1-16

4. Yuan H, Wang LL, Du YZ (2007) Preparation and characteristics of nanostructured lipid carriers for control-releasing progesterone by meltemulsification. Colloids Surf B Biointerfaces 60(2):174-179. https://doi.org/10. 1016/j.colsurfb.2007.06.011
5. Padhye SG, Nagarsenker MS (2013) Simvastatin solid lipid nanoparticles for oral delivery: formulation development and in-vivo evaluation. Indian J Pharm Sci 5(5):591-598 https://www.ncbi.nlm.nih.gov/pmc/articles/PMC3 877522/

6. Hathout RM, Ahmed H (2012) Elshafeey. Development and characterization of colloidal soft nano-carriers for transdermal delivery and bioavailability enhancement of an angiotensin II receptor blocker. Eur J Pharm Biopharm 82:230-240. https://doi.org/10.1016/j.ejpb.2012.07.002

7. Vitorino C, Almeida J (2013) Co-encapsulating nanostructured lipid carriers for transdermal application: from experimental design to the molecular detail. J Control Release 167:301-314. https://doi.org/10.1016/j.jconrel.2013.02.011

8. Schachter M (2004) Chemical, pharmacokinetic and pharmacodynamic properties of statins: an update. Fundamental \& Clinical Pharmacology 19: 117-125. https://doi.org/10.1111/j.1472-8206.2004.00299.x

9. John Coates (2000). Interpretation of infrared spectra, a practical approach Encyclopedia of Analytical Chemistry 10815-10837.

10. Pople PV, Singh KK (2011) Development and evaluation of colloidal modified nanolipid carrier: application to topical delivery of tacrolimus. Eur J Pharm Biopharm 79:82-94

11. Fang JY, Fang C-L (2008) Lipid nanoparticles as vehicles for topical psoralen delivery: solid lipid nanoparticles (SLN) versus nanostructured lipid carriers (NLC). Eur J Pharm Biopharm 70:633-640. https://doi.org/10.1016/j.jpb.2008.05.008

12. Brito Raj S, Chandrasekhar KB, Bhaskar Reddy K (2015) Formulation, optimization and in-vitro evaluation of lipid nanoparticles containing antihypertensive drug. Int J Res Pharm Sci 6(2):42-45

13. Ravi PR, Aditya N (2014) Lipid nanoparticles for oral delivery of raloxifene: Optimization, stability, in-vivo evaluation and uptake mechanism. Eur. J. Pharm. Biopharm. 87:114-124 https://doi.org/10.1016/j.ejpb.2013.12.015

14. Sanad RA, Shawky N, Malak A (2010) Formulation of a novel oxybenzoneloaded nanostructured lipid carriers (NLCS). AAPS Pharm Sci Tech. 11(4): 1684-1694. https://doi.org/10.1208/s12249-010-9553-2

15. Brito Raj S, Chandrasekhar KB, Bhaskar Reddy K (2017) Design, development and in-vivo pharmacokinetic evaluation of cardiovascular drug loaded nano structured lipid carrier system. International Journal of Drug Delivery Technology 7(3):190-209

16. Gambhire MS, Bhalekar MR (2011) Statistical optimization of dithranolloaded solid lipid nanoparticles using factorial design. Braz. J. Pharm. Sci. 47(3):503-511 https://doi.org/10.1590/S1984-82502011000300008

17. Singh B, Dahiya M, Saharan V (2005) Optimizing drug delivery systems using systematic 'design of experiments' Part II: retrospect and prospects. Crit Rev Ther Drug Carrier Syst. 22(3):215-293 https://www.ncbi.nlm.nih.gov/ pubmed/15896189

18. Araujo J, Gonzalez Mira E (2010) Optimization and physicochemical characterization of a triamcinolone acetonide-loaded NLC for ocular antiangiogenic applications. Int J Pharm 393:167-175. https://doi.org/10. 1016/j.ijpharm.2010.03.034

19. Limon D, Amirthalingam E (2015) Novel nanostructured supramolecular hydrogels for the topical delivery of anionic drugs. Eur. J. Pharm. Biopharm. 96:421-436. https://doi.org/10.1016/j.ejpb.2015.09.007

20. Parida P, Mishra SC (2016) Development and characterization of ethyl cellulose based microsphere for sustained release of nifedipine. Journal of Pharmaceutical Analysis 6:341-344 https://doi.org/10.1016/j.jpha.2014.02.001

21. Brito Raj S, Lavanya P (2017) Formulation and in-vitro evaluation of acyclovir solid lipid nanoparticles. International Journal of Pharmacy \& Therapeutics 8(2):49-56. https://doi.org/10.13040/IJPSR.0975-8232.6(1).442-52

22. Bharathi M, Sarat Chandra Prasad M (2012) Preparation, in-vitro and in-vivo characterization of valsartan loaded eudragit nanoparticles. Der Pharmacia Sinica 3(5):516-525

23. Shaikh HK, Kshirsagar RV (2015) Mathematical models for drug release characterization: a review. World Journal of Pharmaceutical Research 4(4): 324-338

24. Brito Raj S, Vijay V (2013) Design and In-Vitro evaluation of diclofenacparacetamol dual release transdermal patch. International Journal of Pharmacy \& Therapeutics 4(2):127-133

25. Andrade LM, de Fatima Reis C (2014) Impact of lipid dynamic behavior on physical stability, in-vitro release and skin permeation of genistein-loaded lipid nanoparticles. Eur J Pharm Biopharm. 88:40-47. https://doi.org/10.1016/j.jpb.2014.04.015

26. Wu P-C, Huang Y-B (2000) Evaluation of pharmacokinetics and pharmacodynamics of captopril from transdermal hydrophilic gels in normotensive rabbits and spontaneously hypertensive rats. Int. J. Pharm. 209:87-94. https://doi.org/10.1016/S0378-5173(00)00557-3 
27. Soutoa B, Wissing SA (2004) Evaluation of the physical stability of SLN and NLC before and after incorporation into hydrogel formulations. Eur. J. Pharm. Biopharm. 58:83-90. https://doi.org/10.1016/j.jpb.2004.02.015

28. Vashisth I, Ahad A (2014) Investigating the potential of essential oils as penetration enhancer for transdermal losartan delivery: Effectiveness and mechanism of action. Asian J Pharm sci. 9:260-267

29. Mangesh BR, Prashant U (2016) Solid lipid nanoparticles incorporated transdermal patch for improving the permeation of Piroxicam. Asian J Pharm 10(1):45-50

30. Chen G, Hao B, Dahong J (2015) Pharmacokinetic and pharmacodynamic study of triptolide-loaded liposome hydrogel patch under microneedles on rats with collagen-induced arthritis. Acta Pharmaceutica Sinica 5(6):569-576. https://doi.org/10.1016/j.apsb.2015.09.006

31. Chen C-C, Tsai T-H (2010) Effects of lipophilic emulsifiers on the oral administration of lovastatin from nanostructured lipid carriers: Physicochemical characterization and Pharmacokinetics. Eur. J. Pharm. Biopharm. 74:474-482. https:/doi.org/10.1016/.ejpb. 2009.12 .008

32. Manjunath K Venkateswarlu V (2005) Pharmacokinetics, tissue distribution and bioavailability of clozapine solid lipid nanoparticles after intravenous and intraduodenal administration. J Control Release. 107:215-228. https:// doi.org/10.1016/j.jconrel.2005.06.006

33. Asha Jyothi P, Tejaswi K, Sujitha Parimala S (2013) Spectrophotometric estimation of simvastatin in bulk and tablet dosage form. International Journal of Innovative Pharmaceutical Research 4(1):284-287

34. Dey S, Pradhan PK (2012) Method development and validation of simvastatin by UV spectrophotometric method. Journal of Pharmacy Research 5(12):5380-5382

35. Muralidharan S, Sankarachari J (2012) Bioequivalence study of simvastatin. Open Access Scientific Reports 1(9):2-4

36. Raju KK, Sudhakar B (2014) Factorial design studies and biopharmaceutical evaluation of simvastatin loaded solid lipid nanoparticles for improving the oral bioavailability. ISRN Nanotechnology 2014:1-8 https:/doi.org/10.1155/2014/951016

37. Anwar M, Warsi MH (2011) Enhanced bioavailability of nano-sized chitosanatorvastatin conjugate after oral administration to rats. Eur J Pharm Sci 44: 241-249. https://doi.org/10.1016/j.ejps.2011.08.001.

\section{Publisher's Note}

Springer Nature remains neutral with regard to jurisdictional claims in published maps and institutional affiliations.

\section{Submit your manuscript to a SpringerOpen ${ }^{\circ}$ journal and benefit from:}

- Convenient online submission

- Rigorous peer review

- Open access: articles freely available online

High visibility within the field

- Retaining the copyright to your article

Submit your next manuscript at $\boldsymbol{\nabla}$ springeropen.com 